\title{
논문 2014-09-09
}

\section{국내 조명 환경에서 센서공간을 활용한 이동로봇의 위치인식시스템 개발}

\section{(Development of Location Identification System for Moving Robot in the Sensor Space under KS Illumination Intensity Environment)}

\author{
강 철 웅, 고 석 준* \\ (Chul U. Kang, Seok J. Ko)
}

\begin{abstract}
When a mobile robot performs in unknown environments, a location identification is an essential task. In this paper, we propose a location identification system that uses a sensor space without additional devices on the robot. Also the sensor space consists of a matrix of CDS sensor; when a robot was positioned on the CDS sensor, we can estimate the coordinate of the location by sensing a light. Based on KS illumination standard, experiments are performed in various environments. By evaluating the experimental results, we can show that the proposed system can be applicable to the location identification system of a moving robot.
\end{abstract}

Keywords : Sensor space, CDS(cadmium sulfide) sensor, Mobile robot, Location system

\section{I. 서론}

이동로봇의 위치인식 기술은 가장 핵심적인 부 분이며, 주어진 임무를 성공적으로 수행하기 위해서 는 주변 환경에 대한 위치인식 능력이 있어야 한다 [1]. 이러한 위치인식 기술에는 엔코더 및 자이로센 서를 장착하여 상대위치를 추정하는 방법, 적외선센 서, 비전센서, GPS를 이용한 절대 위치추정 등이 있다 [2-5]. 최근 '지능공간' 혹은 '센서 네트워크 공간'이라고 하는 새로운 개념을 바탕으로 RFID 태 그 또는 바코드를 랜드마크로 사용하여 이동로봇의 위치인식을 구현한 연구가 진행 되었다 [6-11]. 그 러나 이러한 방법들은 로봇에 여러 장비를 추가하 여야 하며, 추가된 장치들에 의하여 로봇은 많은 계 산량을 요구한다. 따라서 본 논문에는 센서공간을 생성하여 로봇에 장비의 추가 없이 위치인식을 할

*Corresponding Author (sjko@jejunu.ac.kr) Received: 20 Jan. 2014, Revised: 27 Jan. 2014. Accepted: 29 Jan. 2014.

C.U. Kang, S.J. Ko: Jeju National University ※ 본 논문은 2013학년도 제주대학교 학술진흥연 구비 지원사업에서 지원하여 연구되었음.
수 있는 시스템을 설계하였다 [12]. 센서 공간은 CDS(cadmium sulfide sensor)의 매트릭스 구조로 설계하였으며, 빛을 감지하는 $\mathrm{CDS}$ 센서의 특성을 이용하여 이동로봇의 위치인식이 가능하도록 개발 하였다. 센서공간이 커질수록 센서의 개수는 많이 필요하기 때문에, 본 논문에서는 고가이면서 고성능 인 센서보다 저가격이면서 성능이 조금 낮은 $\mathrm{CDS}$ 센서를 선택하게 되었다. 이에 따라, $\mathrm{CDS}$ 센서는 빛의 양에 따라 민감하게 반응하기 때문에 우선적 으로 환경변화에 대한 $\mathrm{CDS}$ 센서의 특성을 정확하 게 파악하여야 한다 [13]. 궁극적으로, 본 논문에서 는 센서공간에서 $\mathrm{CDS}$ 센서를 활용한 환경적응형 필터를 개발하고, 그에 따른 위치인식 시스템을 설 계하였다.

본 논문은 다음과 같이 구성된다. 제 파앙에서는 위치인식 시스템의 센서공간에 대한 구성을 소개하 며, $\mathrm{CDS}$ 센서의 출력 특성을 검토한다. 제 피장에 서는 구성된 센서공간의 환경적응형 필터 알고리즘 을 제시하고, 그룹별 $\mathrm{CDS}$ 센서의 출력 특성을 제시 한다. 제 IV장에서는 개발된 위치인식 시스템에 대 한 실험결과를 보여주며, 마지막으로 제 $\mathrm{V}$ 장에서는 본 논문에 대한 결론을 맺는다. 


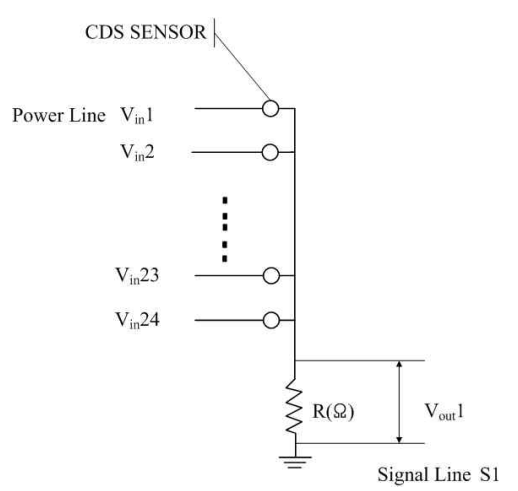

그림 1. $\mathrm{CDS}$ 센서의 회로도

Fig. 1 Circuit of CDS sensor

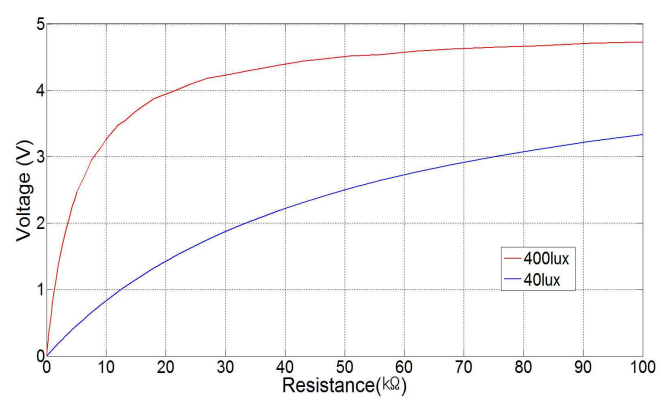

그림 2. 다양한 조도에 따른 저항에 대한 출력전압

Fig. 2 Output voltage vs. resistance value for 40 and 400lux

\section{II . 센서공간의 구성}

본 논문의 위치인식 시스템은 $\mathrm{CDS}$ 센서로 구성 된 센서 공간에 로봇이 위치하면 $\mathrm{CDS}$ 센서의 신호 를 분석하여 로봇의 위치를 판단한다. $\mathrm{CDS}$ 센서는 조도에 따라 저항 값이 변하는 가변저항으로 위치 인식 모듈에 배치된 다수개의 센서정보를 수집하기 위하여 그림 1 과 같이 회로를 설계하였다. 센서공간 을 구성하는 다수의 $\mathrm{CDS}$ 는 그림 1 과 같이 병렬구 조로 구성되어 있으며, 전원선에 순차적으로 $5 \mathrm{~V}$ 의 Vin 전압을 입력하면 전압 분배법칙에 의하여 신호 선에 Vout 전압이 출력된다. 이 때 $\mathrm{CDS}$ 센서는 조 도에 의해 저항이 변하는 가변 저항이므로, 고정 저 항인 R에 의해 $\mathrm{CDS}$ 센서 신호 값이 변할 수 있다.

$\mathrm{CDS}$ 센서의 사용에 있어 가장 중요한 요소는 서 로 다른 조도환경에서 조도변화가 센서 출력으로 충분히 반영되고 있는가를 분석할 필요가 있다. 따 라서 $40 \mathrm{lux}$ 와 400 lux 조도환경에서 고정 저항 값

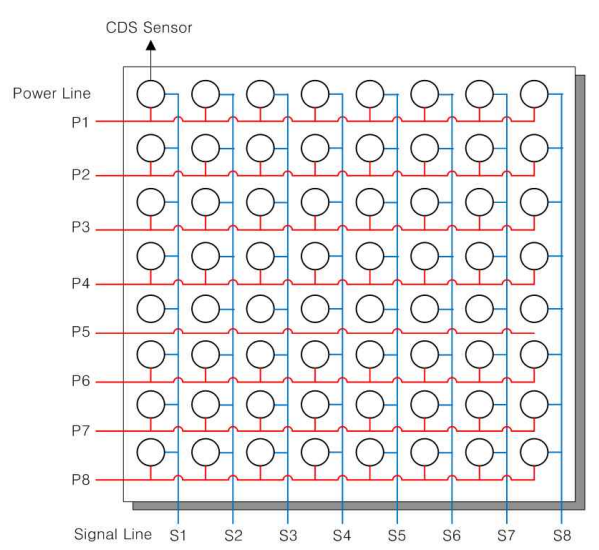

그림 3. 센서공간의 구성

Fig. 3 Construction of sensor space

$\mathrm{R}$ 을 0 부터 $100 \mathrm{k} \Omega$ 까지 변경하면서 측정하였다. 그 림 2 는 $\mathrm{CDS}$ 센서의 출력 값을 측정한 결과이며, $10 \mathrm{k} \Omega$ 부분에서 $\mathrm{CDS}$ 센서 출력변화가 가장 큰 것 을 확인할 수 있다. 위와 같은 센서의 특성분석 결 과를 적용하여, 확장성 및 이동성을 고려한 $8 \times 8$ 의 매트릭스 구조의 센서공간을 그림 3 과 같이 구성하 였다.

8 개의 동일한 입력 행 단자에는 1 개의 전원 신 호선(P)이 연결되며, 동일한 출력 열 단자에는 1 개 의 출력 신호선(S)에 연결되어 있다. 8개의 전원 신 호선(P1, P2, $\cdots, \mathrm{P} 8)$ 은 위치인식모듈에 탑재한 컨트 롤러의 디지털포트에 의해 제어되며, 8개의 출력 신 호선(S1, S2, , S8)은 컨트롤러의 A/D 컨버터 포 트와 디지털포트에 의해 입력된다. 정보 수집을 위 한 회로구동은 센서구동전압을 컨트롤러의 디지털 포트를 통해 1 개의 전원 신호선에 인가해 주면, 8 개의 출력 신호선(S1, S2, $\cdots, \mathrm{S} 8)$ 을 통하여 같은 열 에 배치된 8개의 센서 정보를 동시에 획득할 수 있 다. 결과적으로, 순차적으로 전원 신호선을 P1에서 $\mathrm{P} 8$ 까지 변경하면, 총 64 개의 $\mathrm{CDS}$ 신호를 획득할 수 있다.

\section{III. 센서공간의 환경적응형 필터 알고리즘}

$\mathrm{CDS}$ 의 센서공간은 빛을 감지하는 $\mathrm{CDS}$ 의 특성 때문에 환경변화에 따라 민감하게 반응한다. 따라서 정확한 로봇의 위치인식을 위해서는 환경 적응형 알고리즘이 필수적으로 요구되어진다. 구성된 $\mathrm{CDS}$ 센서 공간은 그림 4 와 같이 2 열씩 그룹화 하는 과 정을 수행하게 되면, 동일한 센서공간을 면적영역으 


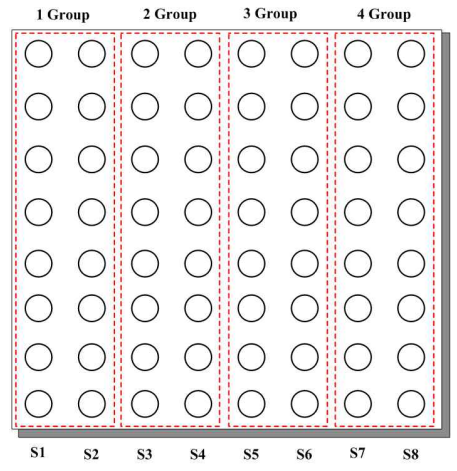

그림 4. 그룹화 된 센서공간

Fig. 4 Grouped sensor space

로 분리하게 되므로 각 영역에 대해 유연하게 조도 환경에 대처할 수 있다.

그룹화 된 센서공간을 $350 \mathrm{lux}$ 의 조도 환경에서 각 그룹의 센서들을 평균하여 시간에 따라 나타내 면 그림 5 와 같다.

위치인식모듈 위에 아무 물체가 없을 경우, 동일 한 조도환경이더라도 그룹별로 $1.72 \sim 1.73 \mathrm{~V}$ 사이 에서 서로 다른 센서출력을 얻을 수 있는 것을 확 인할 수 있다. 따라서 각 영역마다 다른 디지털 비

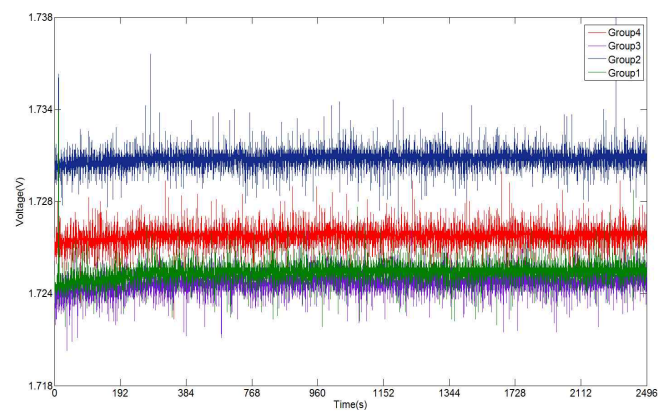

그림 5. 그룹별 $\mathrm{CDS}$ 센서 출력전압

Fig. 5 Average output voltage of the grouped sensor space

교기가 적용되어야 한다. 또한 센서 정보를 획득하 기 위한 보편적인 센싱 방법은 $\mathrm{A} / \mathrm{D}$ 변환 값을 직접 이용하기 때문에, 수백 개의 센서로부터 입력된 $\mathrm{A} / \mathrm{D}$ 변환 값을 얻는 과정에서 소요되는 각각의 $\mathrm{A} / \mathrm{D}$ 변환시간 및 전원공급 지연을 고려하여야 하므 로 로봇의 이동속도를 추종할 수 없는 문제점이 있 다. 따라서 그림 6 과 같이 센서공간의 그룹화 된 아 날로그 신호를 2진화로 표현된 디지털 센서정보로 변환하여 조도환경에 따라 유연하게 적응할 수 있 는 환경 적응형 알고리즘을 개발하였다.

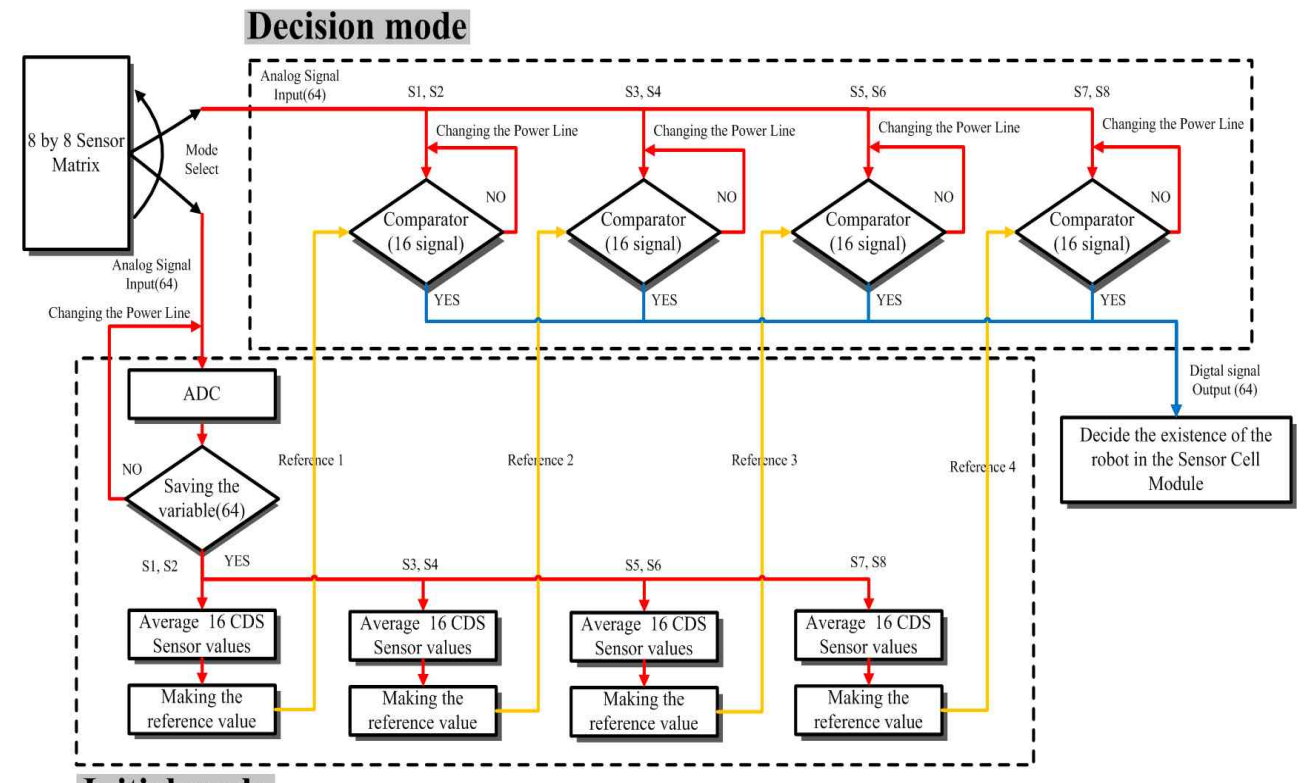

Initial mode

그림 6. 환경 적응형 알고리즘

Fig. 6 Sensor algorithm adapted to environment 


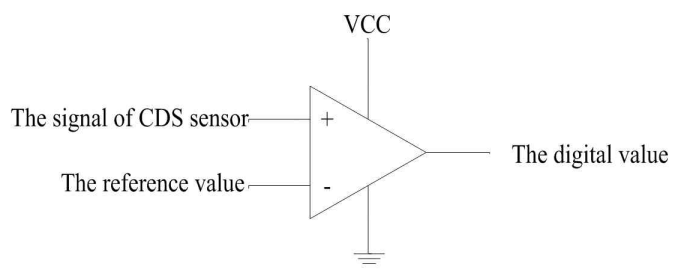

그림 7. 디지털 비교기

Fig. 7 Digital Comparator

표 1. 그룹별 기준 값

Table 1. Reference value of each sensor group

\begin{tabular}{|c|c|c|}
\hline 구분 & Comparator 입력값(v) & Reference(v) \\
\hline group1 & 1.725 & 0.8625 \\
\hline group2 & 1.730 & 0.8650 \\
\hline group3 & 1.724 & 0.8620 \\
\hline group4 & 1.727 & 0.8635 \\
\hline
\end{tabular}

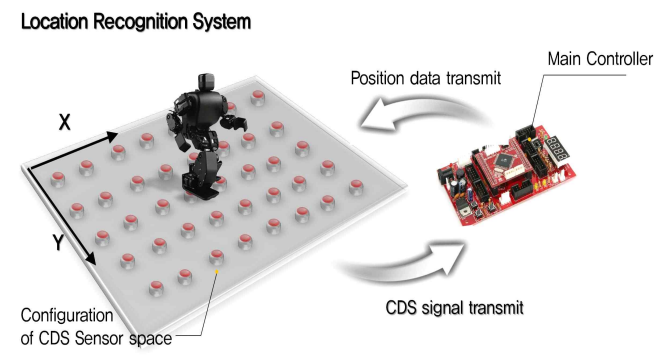

그림 8. 위치인식 모듈의 정보흐름 구조

Fig 8. Flow diagram of the location identification module

그림 6에 제시된 환경 적응형 알고리즘의 작동 은 최초 1 회에 한해 공연장소의 조도환경을 점검하 기 위하여 컨트롤러는 초기 모드(Initial Mode)가 되어 구동된다. 이 과정에서 컨트롤러는 $\mathrm{A} / \mathrm{D}$ 변환 기를 이용하여 출력 신호선(S1, S2, $\cdots, \mathrm{S} 8)$ 로부터 1 회에 8 개 센서의 정보를 8 회 반복하여 총 64 개의 센서정보를 획득한다. 초기 모드에서는 64 개의 센 서정보들에 대한 평균값의 $50 \%$ 에 해당하는 값을 각 그룹의 디지털 비교기에 필요한 기준 값 (Reference value)으로 결정한다. 다음 과정으로, 환경 적응형 알고리즘이 결정 모드(Decision Mode)로 전환되면, 초기 모드에서 결정된 기준 값 은 그림 7에서와 같이 디지털 비교기의 (-)단자 입 력으로 사용된다. 표 1은 $350 \mathrm{Lux}$ 의 조도환경에서
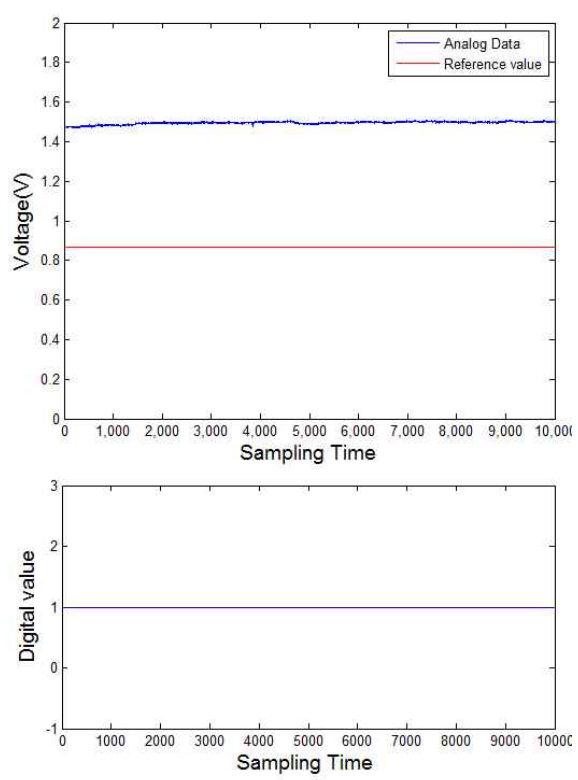

그림 9. 센서공간을 환경에 그대로 노출된 상태에서의 위치인식 시스템의 출력

Fig. 9 Output of the location identification module for open environment
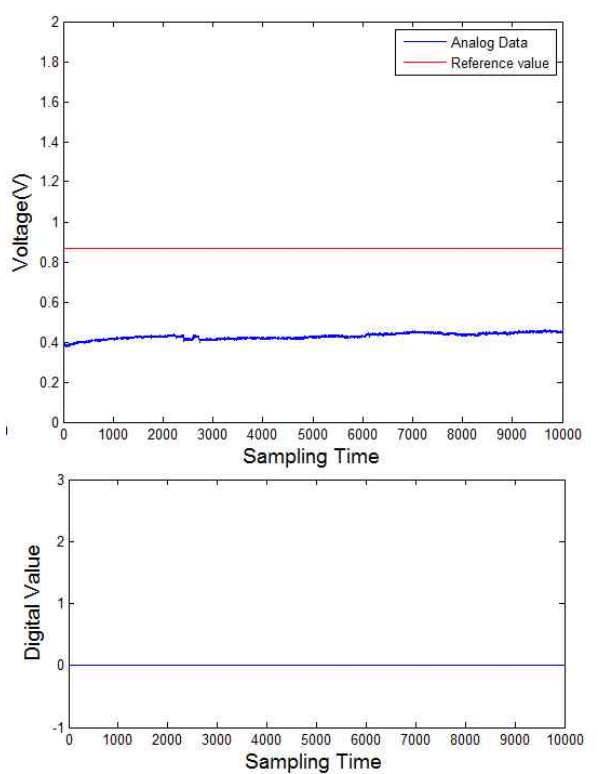

그림 10 센서공간의 광을 완전히 차단한 상태에서의 위치인식 시스템의 출력

Fig. 10 Output of the location identification module for dark environment 
결정된 기준 값을 나타낸다.

전원 신호선이 초기 모드에서 결정 모드로 변환 되면서 비교기의 출력 데이터를 획득할 수 있게 된 다. 즉, $\mathrm{CDS}$ 센서로부터 수신되는 신호 값(S1, S $2, \cdots, \mathrm{S} 8$ )이 비교기에 인가된 기준 값보다 높으면 비교기의 출력은 ' 1 '이 되며, 반대로 낮으면 ' $O$ '의 값을 출력한다. 결과적으로, 비교기의 출력값이 ' 1 ' 이면 로봇이 존재함을 의미하는 것이기 때문에 이 정보를 이용하면 로봇의 위치를 파악할 수 있다.

\section{IV. 실험 결과}

II 장에서 구현한 센서공간의 위치인식의 정보 흐름은 그림 8 과 같다.

위치인식 모듈은 그림 8 과 같이 로봇과 완전히 독립적인 장치로, 컨트롤러(Main controller)에 의 하여 센서 정보 수집 및 환경 적응형 알고리즘을 수행한다. 그림 9 과 10 은 위치인식모듈의 1 개의 센 서에 대한 실제 센서정보의 전압 값(Analog Data) 과 디지털 비교기를 통해 2진화된 센서 정보를 나 타내고 있다. 그림 9는 센서모듈을 환경에 노출한 경우로 로봇이 존재하지 않은 경우를 의미하며, 그 림 10은 빛을 차단한 경우로 로봇이 존재하는 경우 에 대한 결과이다. 관측한 전구간(Sampling Time) 에 대해, 환경에 노출한 경우는 $\mathrm{CDS}$ 센서정보 값 이 디지털 비교기의 기준값 이상으로 나타나며 디 지털 비교기의 출력이 “ 1 ”로 변환된다. 반대로, 빛 을 차단한 경우는 전구간에 대해 디지털 비교기의 기준값 이하로 나타나며 디지털 비교기의 출력은 “0”으로 변환됨을 알 수 있다. 결과적으로, 로봇에 의하여 $\mathrm{CDS}$ 센서가 가려지는 경우 로봇의 위치를 판단할 수 있게 된다.

또한 다양한 환경에 따른 특성을 분석하기 위하 여 $\mathrm{KS}$ 조도 기준에 의하여 환경을 설정하였고, 각 환경에서 위치인식모듈의 센서신호를 판단하는 실 험을 수행하였다. 그 결과는 표 2 와 그림 11 과 같 다.

$\mathrm{KS}$ 조도 등급에 따라 교실, 사무실, 강당, 체육 관, 회의실 등의 환경을 지정하였다. 실험 결과로부 터 환경이 급격하게 변하지 않으면 $\mathrm{CDS}$ 센서 값은 일정하게 유지한다는 것을 알 수 있었다. 따라서 디지털 비교기의 기준 값은 그룹별 평균의 중간값 $(50 \%)$ 을 채택하여 기준 값보다 큰 경우는 로봇이 존재하지 않는 것으로 판정한다. 그러나 조명에 의 한 그림자가 위치인식모듈에 영향을 미치는 경우를
표 2. $\mathrm{KS}$ 조도 기준에 따른 환경설정

Table 2. Environment setting for various illuminations in KS standard

\begin{tabular}{|c|c|c|c|}
\hline 조도 & $\begin{array}{c}\text { 센서 데이터 } \\
\text { 평균 }\end{array}$ & $\begin{array}{c}\mathrm{KS} \text { 조도 } \\
\text { 기준 }\end{array}$ & 설정환경 \\
\hline 0 & $0 \mathrm{v}$ & $\mathrm{A}$ & 로봇 인식 \\
\hline 40 & $0.4409 \mathrm{v}$ & \multirow{2}{*}{$\mathrm{D}$} & \multirow{2}{*}{ 그림자로 인식 } \\
\hline 60 & $0.7019 \mathrm{v}$ & & \\
\hline 80 & $0.8961 \mathrm{v}$ & \multirow{3}{*}{$\mathrm{E}$} & \multirow{3}{*}{ 복도, 회의실 } \\
\hline 100 & $0.9619 \mathrm{v}$ & & \\
\hline 150 & $1.1156 \mathrm{v}$ & & \\
\hline 170 & $1.2617 \mathrm{v}$ & \multirow{4}{*}{ F } & \multirow{4}{*}{ 강당, 체육관, 회의실 } \\
\hline 210 & $1.3781 \mathrm{v}$ & & \\
\hline 250 & $1.5417 \mathrm{v}$ & & \\
\hline 300 & $1.6811 \mathrm{v}$ & & \\
\hline 350 & $1.7166 \mathrm{v}$ & \multirow{4}{*}{ G } & \multirow{4}{*}{ 교실, 사무실 } \\
\hline 400 & $1.7899 \mathrm{v}$ & & \\
\hline 450 & $1.8810 \mathrm{v}$ & & \\
\hline 500 & $1.8999 \mathrm{v}$ & & \\
\hline
\end{tabular}

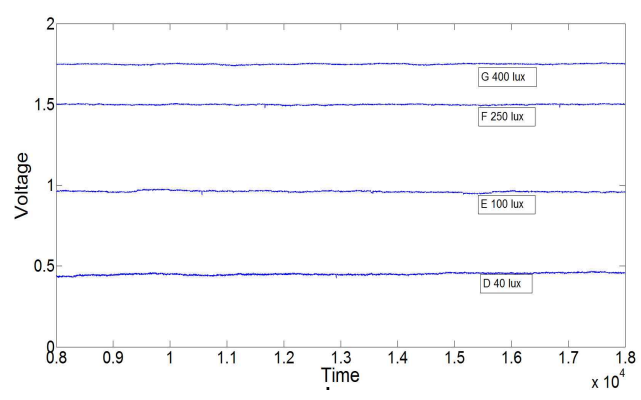

그림 11. 조도등급에 따른 위치인식 센서 모듈의 출력 전압

Fig. 11 Outputs of the location identification module for various illuminations in $\mathrm{KS}$ standard

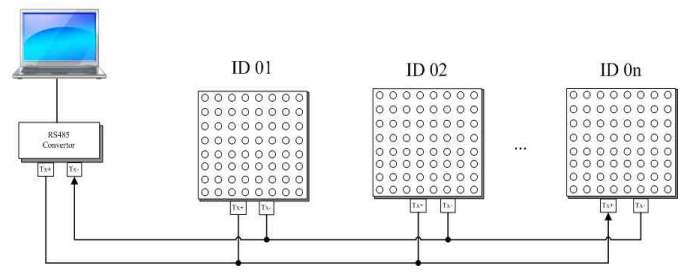

그림 12. 위치인식 시스템의 통신방식

Fig. 12 Communication method of the location identification system

고려하면, 그룹별 평균의 중간값보다 $\mathrm{D}$ 등급의 값을 디지털 비교기의 기준 값으로 설정하여야 더욱더 정확한 로봇의 위치를 인식할 수 있었다. 따라서 위치인식 시스템이 초기 모드에서 공연환경을 결정 
할 때, 그룹별 평균에 대한 각각의 조도등급을 판 단하여 환경에 적응할 수 있는 환경 적응형 알고리 즘을 개발하게 되었다.

이와 같은 기본적인 실험 결과를 바탕으로 다수 의 위치인식 모듈을 결합하여 $2 \mathrm{~m} \times 2 \mathrm{~m}$ 크기로 제 작하여 위치인식 시스템을 개발하였다. 위치인식 모듈에서 수집되는 센서정보를 컴퓨터로 전송하기 위하여 1 대 $\mathrm{n}$ 통신이 가능한 RS485 통신방법을 사용하여 그림 12 와 같이 위치인식 시스템의 통신 방식을 설정하였다.

\section{V. 결 론}

본 논문에서는 기존의 위치인식 방법과는 달리 로봇과는 완전히 독립적인 장치로 구성하여 위치인 식에 대한 불필요한 계산량을 개선하였다. 그리고 센서공간을 갖는 위치인식 모듈을 제작하였으며, 다수의 위치인식 모듈을 연결하여 위치인식 시스템 을 개발하였다.

$\mathrm{CDS}$ 센서로 구성된 센서공간은 환경변화에 따 라 민감하게 반응하므로 정확한 위치인식을 위한 환경 적응형 알고리즘을 포함하였다. 제안된 환경 적응형 알고리즘은 동일한 센서공간을 면적영역으 로 분리함으로서 각 영역에서 유연하게 조도환경에 대응할 수 있는 위치인식 방법이다. 디지털 비교기 에 의하여 아날로그 센서 신호를 디지털로 2진화로 변환하여 처리 속도 및 위치인식의 정확성을 향상 시켰다. 위치인식 시스템을 통하여 얻은 로봇의 위 치정보는 로봇의 이동에 영향을 주며, 추후에는 로 봇과 위치인식 시스템과의 연동을 통해 로봇 위치 추정을 위한 알고리즘을 개발할 계획이다.

\section{References}

[1] K. Pahlavan, X. Li, "Indoor Geolocation science and technology," IEEE Communications Magazine, Vol. 40, No. 2, pp.112-118, 2002.

[2] K. Komoriya, E. Oyama, "Position estimation of a mobile robot using optical fiber gyroscope," Proceedings of IEEE/RSJ/G International Conference on Intelligent Robots and Systems, Vol. 1, pp.143-149, 1994.

[3] S.Y. Lee, J.B. Song, "Robust mobile robot localization using optical flow sensors and encoders," Proceedings of IEEE International Conference on Robotics and Automation, Vol. 1, No. 26, pp.1039-1044, 2004.

[4] Y.S. Ro, K.S. Park, "A study of Optimal Position Estimation for Mobile Robots," Journal of Engineering Research, Vol. 26, No. 1, pp.243-257, 1995.

[5] S.T. Kwon, S.H. Park, M.G. Joo, "An Indoor User-Tracking Mobile Robot Based on Infrared Signal Detection," Journal of IEMEK, Vol. 7, No. 1, pp.25-31, 2012 (in Korean).

[6] K. Morioka, J.H. Lee, H. Hashimoto, "Human-Following Mobile Robot in a Distributed intelligent Sensor Network," IEEE Transaction on Industrial Electronics, Vol. 51, No. 1, pp.229-237, 2003.

[7] K. Kodaka, H. Niwa, Y. Sakamoto, M. Otake, Y. Kanemori, S. Sugano, "Pose Estimation of a Mobile Robot on a Lattice of RFID Tags," Proceedings of IEEE/RSJ International Conference on Intelligent Robots and Systems, pp.1385-1390, 2008.

[8] S.S. Han, H.S. Lim, J.M. Lee, "An Efficient Localization Scheme for a Differential Driving Mobile Robot Based on RFID System," IEEE Transaction on Industrial Electronics, Vol. 54, No. 6, pp.3362-3369, 2007.

[9] J.W. Huh, W.S. Chung, S.Y. Nam, W.K. Chung, "Mobile Robot Exploration in Indoor Environment Using Topological Structure with Invisible Barcodes," ETRI journal, Vol. 29, No. 2, pp.189-200, 2007.

[10] S.H. Park, S. Hashimoto, "Indoor Localization for autonomous mobile robot based on passive RFID," Proceedings of IEEE International Conference on Robotics and Biomimetics, pp.1865-1861, 2008.

[11] J.H. Lee, M. Hashimoto, "Controlling Mobile Robots in Distributed Intelligent Sensor Network," IEEE Transaction on Industrial Electronics, Vol. 50, No. 5, pp.890-902, 2003.

[12] S.S. Lim, S.J. Ko, J.H. Lim, C.U. Kang, "Sensor Data Filtering Algorithm for Efficient Local Positioning System," Software engineering research management and applications, Vol. 430, pp.185-194, 2012. 
[13] S.J. Ko, S.S. Lim, C.U. Kang, "Experiments on the Sensor Space Based Location Estimation System under KS Specified Illumination Intensity Environment," Proceedings of International Conferences on ASEA and DRBC, Vol. 340, pp.225-232, 2012.

\section{저 자 소 개}

\section{강 철 웅}

1996년 일본 나가사키대학 석사.

1999년 일본 나가사키대학 공학박사.

1999년 일본 나가사키대학 문부교관.

현재 제주대학교 메카드로닉스공학전공 교수.

관심분야: 임베디드 하드웨어, 메카트로닉스, 전기전자공학, 의공학.

Email: cukang@jejunu.ac.kr

\section{고 석 준}

1996년 성균관대 전자과 학사.

1998년 성균관대 전자과 석사.

2001년 성균관대 전기전자 및 컴퓨터공학부 공학박사.

현재, 제주대학교 부교수.

관심분야: 임베디드 소프트웨어, 디지털 신호 처리, 무선통신, 레이더.

Email: sjko@jejunu.ac.kr 